\title{
The role of inflammation in metabolic syndrome
}

\author{
Cristina Cuda
}

\begin{abstract}
This manuscript was prepared for NUTR*4350 Current Issues in HBNS under the supervision of Mark Dekker, Department of Human Health and Nutritional Sciences, College of Biological Sciences.
\end{abstract}

\begin{abstract}
The metabolic consequences of obesity have made this highly prevalent condition one of the most common risk factors for type 2 diabetes, hypertension and atherosclerosis. Simultaneous occurrence of these conditions can be explained through the manifestations of metabolic syndrome [MetS]. Clinical indication of MetS is characterized by a clustering of risk factors for complex chronic diseases which all feature metabolic deterioration as a common component. Diagnosis of MetS can be made if a patient exhibits three of the identified risk factors, some of which include: elevated waist circumference, elevated triglycerides, low high density lipoprotein levels, hypertension and elevated blood glucose. The progression from obesity to MetS involves an alteration in body metabolism mediated by cytokinessignalling molecules that coordinate the inflammatory response. Increased visceral adipose tissue contributes to augmented secretion of pro-inflammatory cytokines which can activate several transcription factors, including NF- $\kappa \mathrm{B}$, which promote these inflammatory conditions and lead to increased oxidative stress. Exacerbation of the condition then ensues as oxidative stress results in oxidized low density lipoprotein, dyslipidemia, insulin resistance, hypertension and atherogenesis. This review will not only focus on the role of inflammation in the manifestations of MetS, but also outlines some lifestyle and nutritional treatments that can be used to treat the condition and reduce the risk of chronic disease.
\end{abstract}

$\mathrm{M}$ odern North American lifestyles have brought great changes in diet and physical activity that correlate with an increased incidence of cardiovascular disease and insulin resistance. As diets become more caloric and lifestyle more sedentary, excess weight and obesity has reached levels of $23 \%$ of the Canadian population. This has been accompanied by a $138 \%$ and $60 \%$ increase in men and women, respectively, in chronic diseases that can be attributed to the excess weight from 1970-2004. ${ }^{50}$ Metabolic syndrome [MetS] is a clustering of risk factors for such chronic disease as cardiovascular disease and Type 2 diabetes and is associated with abdominal obesity. ${ }^{25}$ Mechanisms linking the emergence of these chronic conditions to excess weight seem to be related to a state of chronic low-grade inflammation in these individuals. ${ }^{36}$

Classically, inflammation is described as the response of the body when invoked to deal with injury. It is often of short duration and critical to tissue repair. ${ }^{47}$ Its coordination is mediated by the integration of many chemical signals [cytokines] released from different tissues, which are also chronically expressed during obesity and MetS, although few of the other classic symptoms of inflammation are observed. This distinct type of chronic inflammation is primarily triggered by nutrients and metabolic surplus and initiates similar cytokines and signaling pathways as found in classical inflammation. The role of these cytokines in these metabolic diseases is still uncertain; however, they may be the result of fundamental biological design.

The abilities to withstand starvation and the effectively respond and defend against pathogens are critical to species survival. The combination of these desired traits is likely to have given rise to the development of biological organization that is very capable of processing and storing energy as well as expression of a powerful immune response. ${ }^{36}$ The relationship between the immune and metabolic response has been suggested to possibly stem from this idea as well as other evolutionary events. It is important to recognize that functional units that control metabolic and immune functions in higher organisms have evolved from common ancestral structures. For example, the Drosophila fat body incorporates mammalian homologues of the liver and haematopoietic and immune systems. ${ }^{48,67}$ The fly's fat body not only coordinates metabolic responses to nutrients, but also coordinates pathogen response with metabolic status. Although the adipose tissue, liver and haematopoietic system have developed into distinct functional units in humans, they still share a developmental heritage with earlier organisms. It then becomes possible for a situation of overlapping pathways regulating both the immune and metabolic responses with common key regulatory molecules and 
signaling systems to exist. ${ }^{36}$ The mechanisms by which metabolic influences can elicit an immune response involve inflammatory cytokines which can initiate several pathways leading to an increased risk for chronic disease. Of particular interest is the relationship between cytokines and the activation of nuclear transcription factor- $\kappa \mathrm{B}[\mathrm{NF}-\kappa \mathrm{B}]$, which seems to have a role in MetS.

\section{NUCLEAR TRANSCRIPTION FACTOR - KB}

NF- $\kappa B$ regulates the transcriptional activity of at least 125 genes, most of which are pro-inflammatory. ${ }^{79}$ Many of the peripheral actions of cytokines released from adipose tissue [adipokines] are mediated through the activation of NF- $\kappa B$, and its action is further promoted by the effects of other hormones, metabolites and inflammatory cytokines present in MetS. ${ }^{68}$ Through the example pathway illustrated in Figure 1, it can be seen how adipokines can act to induce or suppress the transcription of various factors implicated in MetS.

The activation of NF- $\kappa \mathrm{B}$ can increase oxidative stress, providing a link between inflammation and oxidative stressboth crucial to the development of MetS. Reactive oxygen species [ROS] have been implicated in characteristics of MetS, including, hypertension, atherosclerosis, diabetes and even obesity itself. ${ }^{49,77}$

Aside from cytokines, the action of NF- $\kappa B$ can also be affected by insulin, free fatty acid [FFA] and glucose levels in circulation, all of which are elevated in MetS. Elevated FFAs are thought to increase oxidative stress due to increased $\beta$-oxidation and mitochondrial uncoupling which can increase ROS production. ${ }^{28}$ While hyperglycemia has been shown in vitro to increase NF- $\kappa \mathrm{B}$ activation, ${ }^{42}$ insulin acts to decrease its activation. ${ }^{18}$ However, due to the insulin resistance that accompanies MetS, the insulin is unable to have its anti-inflammatory effects, resulting in NF- $\kappa B$ activation. Insulin resistance results in both hyperglycemia and increased circulating FFAs and seems to be one of the promoting agents for low grade chronic inflammation in MetS. Thus, inflammation may be the underlying factor connecting Type 2 diabetes and cardiovascular disease in MetS.

\section{INFLAMMATION AND TYPE 2 DIABETES}

Recent developments in the understanding of insulin's metabolic actions ${ }^{18}$ have resulted in the idea that insulin resistance may be the basis of most features of MetS. ${ }^{17}$ Increased plasma FFA concentrations are key to the pathology of insulin resistance as they interfere with insulin signalling. ${ }^{17}$ Increasing the plasma FFA concentrations in normal subjects, to levels comparable to obese individuals, also results in the induction of oxidative stress, inflammation, impaired vascular reactivity in addition to insulin resistance. ${ }^{72}$ Insulin has been shown to suppress the pro-inflammatory transcription factor NF- $\mathrm{KB} ;{ }^{19}$ however, resistance to insulin action would decrease this antiinflammatory effect. As seen previously, one way by which $\mathrm{NF}-\mathrm{\kappa B}$ mediates its inflammatory response is through the action of cytokines. If insulin is unable to suppress this action at tissues, such as adipose, cytokine release can increase.

Visceral adipose tissue is thought to be the origin of this inflammation $^{74}$ as increases in weight causes a gradual infiltration of adipose tissue with macrophages. In fact, data from animal studies have shown that the adipose tissue from obese animals contains a significantly higher number of macrophages compared to lean controls. ${ }^{74}$ Both macrophages and adipocytes are capable of releasing cytokines as eliciting an inflammatory response, and the accumulation of adipose tissue is implicated in the development of MetS via its secreted factors.

\section{Tumour Necrosis Factor- $\alpha$ [TNF- $\alpha$ ]}

Within adipose tissue, associated macrophages account for nearly all of the TNF- $\alpha$ production ${ }^{76}$ and both TNF- $\alpha$ mRNA and production increase in the adipose tissue of obese individuals. ${ }^{38}$ TNF- $\alpha$ is a pro-inflammatory cytokine as it activates NF- $\mathrm{kB}$, leading to increased oxidative stress and further cytokine production in peripheral tissues. It has also been associated with an increase in liver and muscle insulin resistance ${ }^{46}$ but this may be an indirect result of its paracrine action in adipose tissue. TNF- $\alpha$ causes adipocyte insulin resistance via serine phosphorylation of both the insulin receptor and insulin receptor substrate within adipose tissue. This results in decreased phosphoinositol-3-kinase activity, an essential secondary messenger in insulin signalling. ${ }^{40}$ This impairment in insulin action has also been shown to occur in skeletal muscle via a paracrine action of TNF- $\alpha$ from the macrophages in myocyte associated fat deposits. ${ }^{37}$ However, this same mechanism has not been found to occur with hepatocytes. ${ }^{39}$

A second potential mechanism of TNF- $\alpha$ action may be its antagonistic effects on the release of another cytokine, adiponectin. Adiponectin is an anti-inflammatory cytokine whose secretion has been shown to be decreased by TNF- $\alpha$ signalling. ${ }^{44}$ Adiponectin is important in increasing insulin sensitivity which may explain how paracrine effects of TNF$\alpha$ can affect systemic insulin sensitivity.

\section{Adiponectin}

Adiponectin consists of both a collagenous tail and globular head which can circulate as high molecular weight complexes, trimer-dimers or just globular heads. ${ }^{74}$ With increasing obesity, adiponectin expression in visceral adipose decreases, ${ }^{74}$ which may lead to the decreased serum concentrations observed and may be due to the increase in TNF- $\alpha$ released from adipose. Administration of either full 


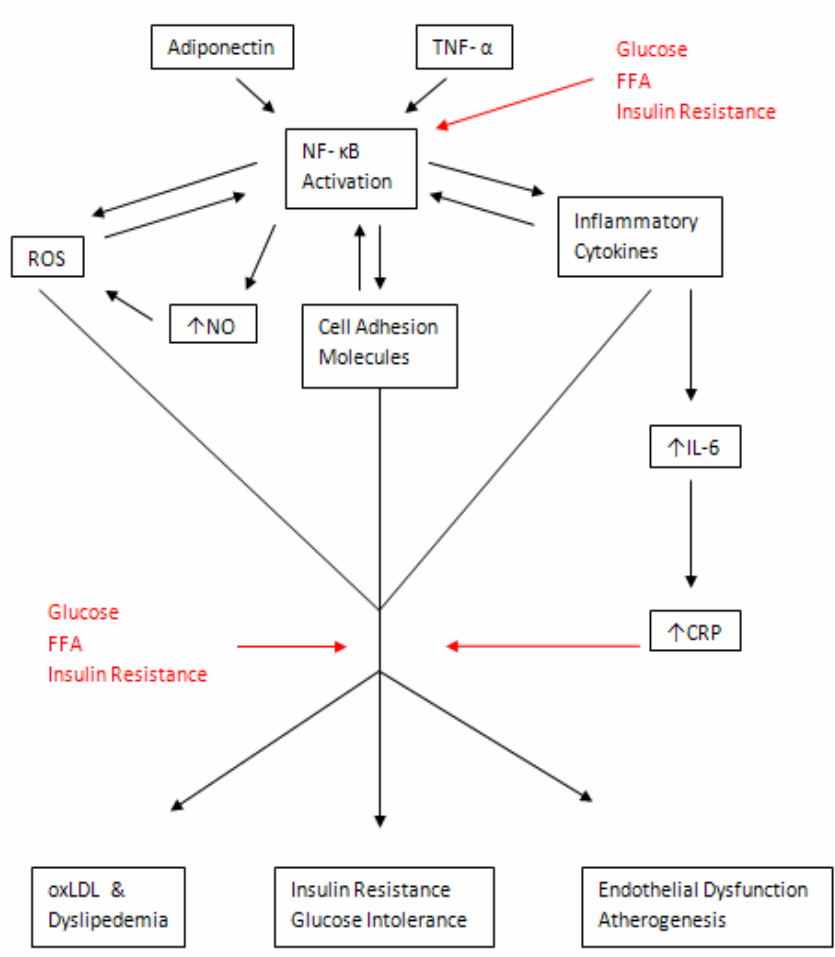

Figure 1: Role of adipokines in increasing NF- $\mathrm{KB}$ activation and clinical manifestations of Metabolic Syndrome (Adapted from Sonnenberg et al., 2004).

length or globular head adiponectin has been shown to decrease plasma glucose and increase insulin sensitivity in mice models of obesity and insulin resistance. ${ }^{5}$

The insulin sensitizing effects of globular adiponectin appears to be mediated by an increase in FFA oxidation via activation of AMP-activated protein kinase [AMPK]in skeletal muscles. ${ }^{82}$ In addition, full length adiponectin also activates AMPK in the liver, reducing hepatic glucose production and increasing glucose uptake. ${ }^{80}$ Adiponectin elicits its response by binding to adipoR1 or AdipoR2 receptors, which are found either in the muscle or liver. ${ }^{81}$ Signalling mechanisms from these receptors have not yet been conclusively deciphered.

\section{Leptin}

Leptin acts similarily to adiponectin in that it increases insulin sensitivity via AMPK activation; however, leptin also has beneficial effects on the central nervous system and food intake regulation. Mature adipocytes secrete leptin proportionally to the amount of adipose mass as well a nutritional status. ${ }^{74}$ The leptin released acts in an endocrine fashion, binding to its receptor in the hypothalamus, muscle and pancreatic $\beta$-cells. ${ }^{74}$ Leptin's primary role is to signal nutrient sufficiency and it has been shown to reduce food intake, body weight and adipose tissue in $o b / o b$ mice. $^{74}$ However, in obese individuals, leptin concentrations are elevated and it is hypothesized that there may be some defect in leptin signalling or transport across that blood-brain barrier. ${ }^{74}$

As a result of leptin's conflicting abundance in obese individuals and the coexistence of insulin resistance and obesity, a correlation between insulin and leptin signalling has been suggested. ${ }^{15,45,70}$ In isolated rodent islet cells, leptin induces $\beta$-cell proliferation and protects against FFA-induced $\beta$-cell apoptosis. ${ }^{41,57}$ However, chronic exposure of human islets to leptin results in $\beta$-cell apoptosis by reducing levels of interleukin IL- 1 receptor antagonist and IL-1 $\beta$ synthesis and secretion. ${ }^{52}$ In addition, rats that have been overfed exhibit both insulin and leptin resistance. ${ }^{75}$ It appears as though leptin is anti-inflammatory when expressed at normal levels, but chronic high levels of leptin seem to lead to resistance or even detrimental effects.

The progression of insulin resistance has also been associated with an increased risk for cardiovascular disease via cytokine activities which may be caused by the actions of the NF- $\kappa \mathrm{B}$ system. The insulin resistance that results from increased FFA concentrations decreases insulin's ability to decrease NF- $\kappa \mathrm{B}$ activity leading to increased oxidative stress and further cytokine production in immune cells and peripheral tissues. The ROS and cytokines that result also have detrimental effects to cardiovascular function in addition to their effects on energy metabolism.

\section{Inflammation AND CARDiovascular Disease}

Evidence has accumulated over the past decade that suggests the atherosclerotic process is regulated by inflammatory mechanisms. ${ }^{49}$ Insulin resistance plays a key role in the development of $\mathrm{MetS}^{20}$ as it promotes an inflammation which can negatively affect arterial and arteriolar function. ${ }^{2}$ The underlying mechanism of vascular dysfunction, at endothelium and smooth muscle levels, appears to be secondary to the excessive ROS generated which seems to be increased by adipokines. ${ }^{1}$ Promotion of the NF- $\kappa \mathrm{B}$ inflammatory pathway plays an important role in the development of chronic subclinical vascular inflammation, resulting in endothelial dysfunction and later the formation of an unstable atherosclerotic plaque, rich in inflammatory cells.

\section{ENDOTHELIAL DYSFUNCTION}

Endothelial dysfunction is the earliest event in atherogenesis. ${ }^{83}$ Key events include the adhesion of leucocytes to the vascular endothelium and subsequent migration into the intima. Rolling and adhesion of leucocytes on the endothelium are triggered by the expression of cell adhesion molecules (CAMs) on the endothelial cells. ${ }^{49,64}$ CAMs expressed in early atherogenesis and also associated with MetS are vascular cell adhesion 
molecule 1 [VCAM-1], intercellular adhesion molecule 1 [ICAM-1] and E-selectin. Prospective surveys of individuals with MetS have found that the levels of soluble endothelial adhesion molecules are higher in patients with MetS when compared to controls. ${ }^{6}$ CAM levels can also be affected by the cytokine adiponectin, ${ }^{65}$ accounting for some of its antiinflammatory actions.

\section{Dyslipidemia and Unstable Atheroscerotic Plaques}

An increased expression of CAMs leads to enhanced recruitment of monocytes within the arterial wall. ${ }^{83} \mathrm{An}$ unstable plaque is prone to rupture leading to thrombus formation and vessel wall occlusion. An abundance of macrophages and other inflammatory cells are hallmarks of unstable atherosclerotic plaques. ${ }^{83}$

Abnormalities in lipoprotein distribution also contribute to the instability of a plaque. Triglyceride rich lipoproteins, their remnants, and smaller, denser, low-density lipoprotein [LDL] particles all have potentially inflammatory actions when they interact with the arterial wall. ${ }^{16,22}$ In contrast, high-density lipoproteins [HDL] appear to have antiinflammatory actions. ${ }^{83}$ The lipoprotein profile of MetS is characterized by an increase in pro-inflammatory lipoproteins and low concentration of anti-inflammatory HDL particles. ${ }^{83}$ The elevated atherogenic potential of LDL particles is mostly accounted for by their increased susceptibility to oxidation. ${ }^{12}$ A study of healthy men found that MetS was accompanied by high plasma concentrations of oxidized LDL [oxLDL] compared to those without. ${ }^{66}$ The oxLDL levels were associated with most of the MetS risk factors and also related to small LDL particle size. Levels of oxLDL are interrelated with the NF- $\mathrm{KB}$ pathway as cytokine levels and other markers of inflammation modulate oxLDL levels and oxLDL also acts to further stimulate NF$\kappa \mathrm{B}$ and produce more ROS. ${ }^{53}$

\section{C-Reactive Protein [CRP]}

CRP levels are strongly correlated with inflammation and atherosclerosis and are also elevated in MetS. This has been demonstrated in various studies, including a survey of freeliving individuals without diabetes or clinical coronary artery disease. The results showed that CRP positively correlated with body mass index [BMI], waist circumference, blood pressure, triglycerides, fasting insulin and blood glucose levels; it also inversely correlated with HDL levels. ${ }^{31}$ CRP is an inflammatory marker produced by the liver under stimulation by cytokines IL- 6 and TNF- $\alpha{ }^{78,83}$ It attaches to the plasma membrane of damaged cells and causes cell death through activation of the complement cascade. ${ }^{63}$ CRP also enhances the uptake of LDL at the endothelium and stimulates macrophages to express cytokines, ${ }^{86}$ while plasma levels have been correlated with levels of CAMs. ${ }^{61}$ In addition, CRP may also participate directly in the cell wall mechanisms leading to atherosclerotic lesions and cardiac events. ${ }^{9}$

\section{Tumour Necrosis Factor- $\alpha$ [TNF- $\alpha$ ]}

TNF- $\alpha$ has been implicated in endothelial dysfunction as it has been shown to increase leukocyte adhesion to the endothelium, ${ }^{84}$ activate NF- $\kappa \mathrm{B}$ dependent inflammatory pathways, ${ }^{3}$ induce endothelial cell expression of VCAM- $1,{ }^{6}$ induce smooth muscle expression of metalloproteinases contributing to plaque destabilization ${ }^{73}$ and suppress the expression of nitric oxide synthase ${ }^{29}$ leading to decreased capacity to vasodilate vessels. TNF- $\alpha$ also stimulates the production of IL-6 stimulates hepatic CRP production. ${ }^{8,34}$ Antagonistic to TNF- $\alpha$ action is adiponectin which is present in decreased levels in MetS.

\section{Adiponectin}

In addition to its role in decreasing insulin resistance, adiponectin also appears to be antiatherogenic. It stimulates the production of nitric oxide, ${ }^{14}$ reduces the expression of CAM in endothelial cells and decreases cytokine production from macrophages by inhibiting NF- $\kappa B$ signalling. It further counteracts the pro-inflammatory actions of TNF- $\alpha$ on arterial walls and suppresses the transformation of macrophages into foam cells. ${ }^{4,60}$ Adiponectin expression and secretion from adipose tissue is reduced by TNF- $\alpha,{ }^{43,51}$ possibly through stimulated production of IL- $6,{ }^{35}$ which inhibits adiponectin secretion. ${ }^{30}$ Figure 2 provides an overview of the role of inflammation in MetS.

\section{OTHER FaCtors in THE Metabolic Syndrome}

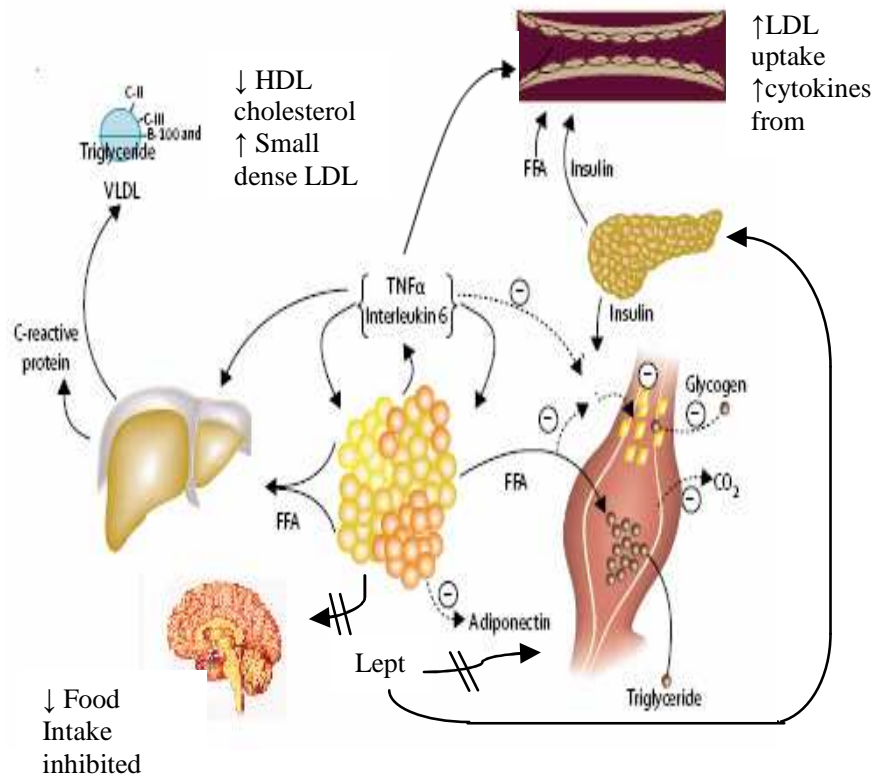

Figure 2: Whole body effects of selected cytokines in the inflammation of Metabolic Syndrome (Adapted from Eckel et al., 2005). 
There are many other components of MetS that can be accounted for by chronic low grade inflammation and the characteristics presented were only briefly reviewed. There are also other cytokines and biomarkers present in MetS that have not been mentioned. Certainly factors associated with blood coagulation and other cytokines are also significant though some are less characterized then ones mentioned.

\section{TREATMENT OPTIONS}

Initial treatment of MetS characteristics should include lifestyle and dietary factors as well as nutritional interventions. Both have been shown to be beneficial and can potentially decrease medical dependence. Teaching individuals with MetS how to promote their own health is important to making good lifestyle choices.

\section{Lifestyle Factors}

Body weight reduction through diet, exercise or surgery has been proven to be beneficial in lowering inflammation and improving MetS characteristics. ${ }^{13}$ In addition, physical activity can influence insulin sensitivity and MetS independent of weight loss. ${ }^{7}$ Several studies have shown that an increase in physical activity can improve, at least in the relatively short term, insulin sensitivity, ${ }^{21}$ with a subsequent decrease in plasma triglyceride levels and increase in HDL cholesterol levels. ${ }^{23}$ Exercise beneficially influences the production of cytokines and adipokines, such as CRP, IL-6 and TNF- $\alpha$, irrespective of changes in total body weight. ${ }^{56}$ Moreover, physical activity reduces plasma concentrations of other inflammatory markers, such as intercellular adhesion molecule-1, VCAM and P-selectin, which are associated with endothelial dysfunction. ${ }^{85}$ Physical activity interventions reduce the prevalence of MetS, ${ }^{58}$ and physical activity is inversely associated with a number of components of the MetS in apparently healthy men. ${ }^{10}$

\section{Dietary Intake}

Macronutrient intake may produce oxidative stress and inflammatory responses. Glucose ingestion in normal subjects is associated with increased superoxide generation in leukocytes and mononuclear cells, as well as with raised amount and activity of NF-kB. ${ }^{17}$ A mixed meal from a fastfood chain has also been shown to induce activation of NF$\kappa \mathrm{B}$ associated with the generation of reactive oxygen species by mononuclear cells. Interestingly enough, superoxide is an activator of at least two major pro-inflammatory transcription factors, including NF- $\kappa \mathrm{B}$. These findings are in line with previous studies demonstrating that after oral or intravenous glucose challenges, in both normal subjects and patients with Type 2 diabetes mellitus, there is an increased generation of ROS and raised circulating levels of inflammatory cytokines, TNF- $\alpha$ and IL- $6 .{ }^{11,27}$
A single high-fat meal in normal subjects produces endothelial activation, as evidenced by increased concentrations of the adhesion molecules VCAM-1 and ICAM-1, in association with raised plasma concentrations of IL-6 and TNF- $\alpha{ }^{54}$ Moreover, the same high-fat meal may increase the circulating levels of IL-18, ${ }^{26}$ a pro-inflammatory cytokine supposed to be involved in plaque destabilization, associated with the simultaneous decrease of circulating adiponectin. $^{71}$

\section{Antioxidants}

An impaired serum redox balance with decreased antioxidant capacity and increased lipid peroxidation has been observed in patients with visceral obesity and MetS. ${ }^{69}$ Increasing the antioxidant content of the diet, either with a Mediterranean diet $^{32}$ or with increased fruit and vegetable consumption, ${ }^{55}$ may be of use in the treatment of MetS. The Mediterranean diet contains high levels of olive oil and vegetables, providing a wide antioxidant capacity. ${ }^{33}$ In a recent controlled crossover trial with an olive oil intervention, lowered plasma oxLDL and lipid peroxide were found, ${ }^{32}$ suggesting that the antioxidants in olive oil may provide some protection against cardiovascular disease risk factors. Most epidemiological studies of fruit and vegetable consumption have found a reduced risk for stroke; ${ }^{55}$ however, experimental and human studies of antioxidant addition to the diets of individuals with MetS have yielded controversial results. ${ }^{33}$

\section{CONCLUSIONS AND FUture RESEARCH}

The proinflammatory state of obesity and MetS probably originates from excessive caloric intake due to overnutrition in most individuals. Inflammation can induce insulin resistance and lead to the manifestations of MetS. Adipokines produced by the excess visceral adipose tissue in obesity also play a central role in manifesting these characteristics of MetS. Future research should aim to further clarify the role of these adipokines in MetS so as to control the actions of these factors and prevent progression of the syndrome. Emphasis should be placed on the roles of proper nutrition and lifestyle to prevent and treat the condition in addition to prescribed medications. This provides the opportunity for individuals to prevent or treat MetS themselves and learn how to better care for their health.

\section{REFERENCES}

1. Andreas, F., D’Agostino, R., Howard, G., Mykkanen, L., Russel, T. and Haffner, S. 2000. Chronic subclinical inflammation as part of the insulin resistance syndrome: the insulin resistance atherosclerosis study (IRAS). Circulation; 102: 42 -7. 
2. Arcaro, G., Cretti, A., Balzano, S., Lechi, A., Muggeo, M., Bonora, E., et al. 2002. Insulin causes endothelial dysfunction in humans: sites and mechanisms. Circulation; 105: 576- 82.

3. Ashton, A.W. et al. 2003. Inhibition of tumor necrosis factor alpha-mediated NFkappaB activation and leukocyte adhesion, with enhanced endothelial apoptosis, by G protein-linked receptor (TP) ligands. Journal of Biological Chemistry; 278: 11858- 11866.

4. Bastard, J.P. Maachi M, Lagathu C, Kim MJ, Caron M, Vidal H, Capeau J, Feve B. 2006. Recent advances in the relationship between obesity, inflammation, and insulin resistance. European Cytokine Network; 17: 412.

5. Berg, A.H., Combs, T.P. and Scherer, P.E. 2002. ACRP30/adiponectin: an adipokine regulating glucose and lipid metabolism. Trends in Endocrinology and Metabolism; 13: 84- 9 .

6. Bonora, E., Kiechl, S., Willeit, J., Bonora E, Kiechl S, Willeit J, Oberhollenzer F, Egger G, Bonadonna RC, Muggeo M; Bruneck Study. 2003. Metabolic syndrome: epidemiology and more extensive phenotypic description. Cross-sectional data from the Bruneck Study. International Journal of Obesity; 27: 1283-9.

7. Brouwer, B.G., Visseren, F.L.J, van der Graaf, Y. 2007. The effect of leisure-time physical activity on the presence of metabolic syndrome in patients with manifest arterial disease. The SMART study. American Heart Journal; 154(6): 1146-1152.

8. Bullo, M., Garcia-Lorda, P., Megias, I. and SalasSalvado, J. 2003. Systemic inflammation, adipose tissue tumor necrosis factor, and leptin expression. Obesity Research; 11: $525-31$.

9. Burke, A.P., Tracy, R.P., Kolodgie, F., Malcom, G.T., Zieske, A., Kutys, R., Pestaner, J., Smialek, J. and Virmani, R. 2002. Elevated C-reactive protein values and atherosclerosis in sudden coronary death: Association with different pathologies. Circulation; 105: 2019- 2023.

10. Carroll, S., Cooke, C.B. and Butterly, R.J. 2000. Metabolic clustering, physical activity and fitness in nonsmoking, middle-aged men. Medicine and Science in Sports and Medicine; 32: 2079-86.

11. Ceriello, A., Taboga, C., Tonutti, L., Quagliaro, L., Piconi, L., Bais, B., Da Ros, R. and Motz, E. 2002. Evidence for an independent and cumulative effect of postprandial hypertriglyceridaemia and hyperglycaemia on endothelial dysfunction and oxidative stress generation. Circulation; 106: 1211- 1218.

12. Chait, A., Brazg, R.L., Tribble, D.L., et al. 1993. Susceptibility of small, dense, low-density lipoproteins to oxidative modification in subjects with the atherogenic lipoprotein phenotype, pattern B. American Journal of Medicine; 94: 350 -6.
13. Chen, H. 2006. Cellular inflammatory responses: novel insights for obesity and insulin resistance. Pharmacology Research; 53: 469- 477.

14. Chen, H. et al. 2003. Adiponectin stimulates production of nitric oxide in vascular endothelial cells. Journal of Biological Chemistry; 278: 45021- 45026.

15. Cohen, B. et al. 1996. Modulation of insulin activities by leptin. Science; 274: 1185-1188.

16. Colome, C., Martinez-Gonzalez, J., Vidal, F., et al. 2000. Small oxidative changes in atherogenic LDL concentrations irreversibly regulate adhesiveness of human endothelial cells: effect of the lazaroid U74500A. Atherosclerosis; 149: 295- 302.

17. Dandona, O., Alijada, A., Chaudhuri, A., Mohanty, P. and Garg, R. 2005. Metabolic Syndrome a comprehensive perspective based on interactions between obesity, diabetes and inflammation. Circulation; 111: 1448- 1454.

18. Dandona, P., Aljiada, A. and Mohanty, P. 2002. The anti-inflammatory and potential anti-atherogenic effect of insulin: a new paradigm. Diabetologia; 45:924-930.

19. Dandona, P., Aljada, A., Mohanty, P., Ghanim, H., Hamouda, W., Assian, E. and Ahmad, S. 2001. Insulin inhibits intranuclear nuclear factor kappaB and stimulates IkappaB in mononuclear cells in obese subjects: evidence for an anti-inflammatory effect? Journal of Clinical Endocrinololgy and Metabolism; 86: 3257- 3265.

20. Deedwania, P.C. 2004. Metabolic syndrome and vascular disease: is nature or nurture leading the new epidemic of cardiovascular disease. Circulation; 109:2 4.

21. DeFronzo, R.A., Sherwin, R.S. and Kraemer, N. 1987. Effect of physical training on insulin action in obesity. Diabetes; 36: 1379- 85.

22. Doi, H., Kugiyama, K., Oka, H., et al. 2000. Remnant lipoproteins induce proatherothrombogenic molecules in endothelial cells through a redox-sensitive mechanism. Circulation; 102: 670 -6.

23. Durstine, J.L., Grandjean, P.W., Davis, P.G., et al. 2001. Blood lipid and lipoprotein adaptations to exercise: a quantitative analysis. Sports Medicine; 31: 1033- 62.

24. Eckel, R.H., Grundy, S.M. and Zimmet, P.Z. 2005. The Metabolic Syndrome. The Lancet; 365: 1415-1428.

25. Esposito, K. and Giugliano, D. 2004. The metabolic syndrome and inflammation: association or causation? Nutrition, Metabolism and Cardiovascular Disease; 14: 228-232.

26. Esposito, K., Nappo, F., Giugliano, F., Di Palo, C., Ciotola, M., Barbieri, M., Paolisso, G. and Giugliano, D. 2003. Meal modulation of circulating interleukin 18 and adiponectin concentrations in healthy subjects and in 
patients with type 2 diabetes mellitus. American Journal of Clinical Nutrition; 78: 1135-1140.

27. Esposito, K., Nappo, F., Marfella, R., Gigliano, G., Giugliano, F., Ciotola, M., Quagliaro, L., Ceriello, A. and Giugliano, D. 2002. Inflammatory cytokine concentrations are acutely increased by hyperglycaemia in humans: role of oxidative stress. Circulation; 106: 2067-2072.

28. Evans, J.L., Goldfine, I.D., Maddux, B.A. and Grodsky, G.M. 2002. Oxidative stress and stress-activated signaling pathways: a unifying hypothesis of type 2 diabetes. Endocrine Review; 23:599-622.

29. Fard, A. et al. 2000. Acute elevations of plasma asymmetric dimethylarginine and impaired endothelial function in response to a high-fat meal in patients with type 2 diabetes. Arteriosclerosis, Thrombosis and Vascular Biology; 20: 2039- 2044.

30. Fasshauer, M., Kralisch, S., Klier, M., et al. 2003. Adiponectin gene expression and secretion is inhibited by interleukin-6 in 3T3-L1 adipocytes. Biochemical and Biophysical Research Communications; 301: 1045- 50.

31. Festa, A., D’Agostino, R. Jr, Howard, G. et al. 2000. Chronic subclinical inflammation as part of the insulin resistance syndrome: the Insulin Resistance Atherosclerosis Study (IRAS). Circulation; 102: 42-7

32. Fito, M., Cladellas, M., de la T.R., et al. 2005. Antioxidant effect of virgin olive oil in patients with stable coronary heart disease: a randomized, crossover, controlled, clinical trial. Atherosclerosis; 181: 149-58.

33. Grattagliano, I., Palmieri, V.O., Portincasa, P., Moschetta, A. and Palasciano, G. 2007. Oxidative stress-induced risk factors associated with the metabolic syndrome: a unifying hypothesis. Journal of Nutritional Biochemistry; Article in Press Sept 12 2007 doi:10.1016/j.jnutbio.2007.06.011.

34. Grunfeld, C., Zhao, C., Fuller, J., et al. 1996. Endotoxin and cytokines induce expression of leptin, the ob gene product, in hamsters. Journal of Clinical Investigation; 97: $2152-7$.

35. Grunfeld, C. and Feingold, K.R. 1991. The metabolic effects of tumor necrosis factor and other cytokines. Biotherapy; 3: 143- 58.

36. Hotamisligil, G.S. 2006. Inflammation and metabolic disorders. Nature; 444: 860- 867.

37. Hotamisligil, G.S., Peraldi, P., Budavari, A., Ellis, R., White, M.F. and Spiegelman, B.M. 1996. IRS-1mediated inhibition of insulin receptor tyrosine kinase activity in TNF-alpha- and obesity-induced insulin resistance. Science; 271: 665-668.

38. Hotamisligil, G.S., Arner, P., Caro, J.F., Atkinson, R.L. and Spiegelman, B.M. 1995. Increased adipose tissue expression of tumor necrosis factor-alpha in human obesity and insulin resistance. Journal of Clinical Investigation; 95: 2409- 2415.
39. Hotamisligil, G.S., Budavari, A., Murray, D. and Spiegelman, B.M. 1994a. Reduced tyrosine kinase activity of the insulin receptor in obesity diabetes. Central role of tumor necrosis factor-alpha. Journal of Clinical Investigation; 94: 1543-1549.

40. Hotamisligil, G.S., Murray, D.L., Choy, L.N. and Spiegelman, B.M. Tumor necrosis factor alpha inhibits signaling from the insulin receptor. Proceedings of the National Academy of Science USA; 91: 4854-4858.

41. Islam, M.S., Sjoholm, A. and Emilsson, V. 2000. Fetal pancreatic islets express functional leptin receptors and leptin stimulates proliferation of fetal islet cells. International Journal of Obesity and Related. Metabolic Disorders; 24: 1246- 1253.

42. Iwasaki, Y., Kambayashi, M., Asai, M., Yoshida, M., Nigawara, T. and Hasimoto, K. 2007. High glucose alone, as well in combination with proinflammatory cytokines, stimulates nuclear factor kappa-B- mediated transcription in hepatocytes in vivo. Journal of Diabetes and Its Complications; 21: 56-62.

43. Kappes A, Loffler G. Influences of ionomycin, dibutyrylcycloAMP and tumour necrosis factor-alpha on intracellular amount and secretion of apM1 in differentiating primary human preadipocytes. 2000. Hormone and Metabolism Research; 32: 548- 54

44. Kern, P.A., Di Gregorio, G.B., Lu, T., Rassouli, N. and Ranganathan, G. 2003. Adiponectin expression from human adipose tissue: Relation to obesity, insulin resistance, and tumor necrosis factor-alpha expression. Diabetes; 52: 1779- 1785.

45. Kim, Y.B. Uotani S, Pierroz DD, Flier JS, Kahn BB. 2000. In vivo administration of leptin activates signal transduction directly in insulin-sensitive tissues: overlapping but distinct pathways from insulin. Endocrinology; 141: 2328- 2339.

46. Lang, C.H., Dobrescu, C. and Bagby, G.J. 1992. Tumor necrosis factor impairs insulin action on peripheral glucose disposal and hepatic glucose output. Endocrinology; 130: 43- 52.

47. Larsen, G.L. and Henson, P.M. 1983. Mediators of inflammation. Annual Review of Immunology; 1: 335339.

48. Leclerc, V. and Reichhart, J.M. 2004. The immune response of Drosophila melanogaster. Immunology Review; 198: 59-71.

49. Libby, P. 2003. Inflammation in atherogenesis. Nature; 420: $868-74$.

50. Luo, W., Morrison, H., de Groh, M., Waters, C., DesMeules, M., Jones-McLean, E., Ugnat, A-M, Desjardins, S., Lim, M. and Mao, Y. 2007. The Burden of Adult Obesity in Canada. Chronic Diseases in Canada; 27(4): 135-44. 
51. Maeda, N., Takahashi, M., Funahashi, T., et al. 2001. PPAR $\gamma$ ligands increase expression and plasma concentrations of adiponectin, an adipose-derived protein. Diabetes; 50: 2094- 9.

52. Maedler, K. and Donath, M.Y. 2004. Beta-cells in type 2 diabetes: a loss of function and mass. Hormone Research; 3(62 suppl): 67-73.

53. Matsunaga, T., Hokari, S., Koyama, I., Harada, T., Komoda, T. 2003. NF-kB activation in endothelial cells treated with oxidized high-density lipoprotein. Biochemical and biophysical research communications; 303: 313-9.

54. Nappo, F., Esposito, K., Cioffi, M., Giugliano, G., Molinari, A.M., Paolisso, G., Marfella, R. and Giugliano, D. 2002. Postprandial endothelial activation in healthy subjects and in type 2 diabetic patients: role of fat and carbohydrate meals. Journal of the American College of Cardiology; 39: 1145-1450.

55. Ness, A.R. and Powles, J.W. 1997. Fruit and vegetables, and cardiovascular disease: a review. International Journal of Epidemiology; 26: 1- 13.

56. Oberbach, A., Tonjes, A., Kloting, N., et al. 2006. Effect of a 4 week physical training program on plasma concentrations of inflammatory markers in patients with abnormal glucose tolerance. European Journal of Endocrinology; 154: 577- 85.

57. Okuya, S. et al. 2001. Leptin increases the viability of isolated rat pancreatic islets by suppressing apoptosis. Endocrinology; 142: 4827- 4830.

58. Orchard, T.J., Temprosa, M., Goldberg, R., et al. 2005. The effect of metformin and intensive lifestyle intervention on the metabolic syndrome: the Diabetes Prevention Program randomized trial. Annals of Internal Medicine; 142: 611-9.

59. Ouchi, N. Kihara S, Arita Y, Maeda K, Kuriyama H, Okamoto Y, Hotta K, Nishida M, Takahashi M, Nakamura T, Yamashita S, Funahashi T, Matsuzawa Y. 1999. Novel modulator for endothelial adhesion molecules: adipocyte-derived plasma protein adiponectin. Circulation; 100: 2473- 2476.

60. Ouchi, N. Kihara S, Arita Y, Okamoto Y, Maeda K, Kuriyama H, Hotta K, Nishida M, Takahashi M, Muraguchi M, Ohmoto Y, Nakamura T, Yamashita S, Funahashi T, Matsuzawa Y. 2000. Adiponectin, an adipocyte-derived plasma protein, inhibits endothelial NF-kappaB signaling through a cAMP-dependent pathway. Circulation; 102: 1296-1301.

61. Pasceri, V., Willerson, J.T. and Yeh, E.T. 2000. Direct proinflammatory effect of C-reactive protein on human endothelial cells. Circulation; 102: 2165-8.

62. Patel, J.N. Patel JN, Jager A, Schalkwijk C, Corder R, Douthwaite JA, Yudkin JS, Coppack SW, Stehouwer CD.(from pubmed) 2002. Effects of tumour necrosis factor-alpha in the human forearm: blood flow and endothelin-1 release. Clinical Science (Lond.); 103: 409- 415.

63. Pepys MB, Hirschfield GM. 2003. C-reactive protein: A critical update. Journal of Clinical Investigation; 111: $1805-1812$.

64. Ross, R. 1999. Atherosclerosis: an inflammatory disease. New England Journal of Medicine; 340: 115 26.

65. Salmenniemi, U., Ruotsalainen, E., Pihlajamaki, J., Vauhkonen, I., Kainulainen, S., Punnoen, K., Vanninen, E. and Laakso, M. 2004. Multiple abnormalities in glucose and energy metabolism and coordinated changes in levels of adiponectin, cytokines, and adhesion molecules in subjects with metabolic syndrome. Circulation; 110: 3842- 3848 .

66. Sigurdardottir, V., Fagerberg, B. and Hulthe, J. 2002. Circulating oxidized low-density lipoprotein (LDL) is associated with risk factors of the metabolic syndrome and LDL size in clinically healthy 58- year-old men (AIR study). Journal of Internal Medicine; 252: 440 -7.

67. Sondergaard, L. 1993. Homology between the mammalian liver and the Drosophila fat body. Trends in Genetics; 9: 193.

68. Sun, Z. and Andersson, R. 2002. NF-אB activation and inhibition: a review. Shock. 2002;18: 99-106.

69. Suthanthiran, M., Anderson, M.E., Sharma, V.K. and Meister, A. 1990. Glutathione regulates activationdependent DNA synthesis in highly purified normal human $\mathrm{T}$ lymphocytes stimulated via the $\mathrm{CD} 2$ and $\mathrm{CD} 3$ antigens. Proceedings of the National Academy of Science USA; 87: 3343- 7.

70. Szanto, I. and Kahn, C.R. 2000. Selective interaction between leptin and insulin signaling pathways in a hepatic cell line. Proceedings of the National Academy of Science USA; 97: 2355- 2360.

71. Tataranni, P.A. and Ortega, E. 2005. A burning question. Does an adipokine-induced activation of the immune system mediate the effect of overnutrition on type 2 diabetes? Diabetes; 54: 917-927.

72. Tripathy, D., Mohanty, P., Dhindsa, S., Syed, T., Ghanim, H., Aljada, A. and Dandona,P. 2003. Elevation of free fatty acids induces inflammation and impairs vascular reactivity in healthy subjects. Diabetes; 52: 2882- 2887.

73. Uzui, H. Harpf A, Liu M, Doherty TM, Shukla A, Chai NN, Tripathi PV, Jovinge S, Wilkin DJ, Asotra K, Shah PK, Rajavashisth TB. 2001. Increased expression of membrane type 3-matrix metalloproteinase in human atherosclerotic plaque: role of activated macrophages and inflammatory cytokines. Circulation; 106: 30243030.

74. Vettor, R., Milan, G., Rossato, M. and Federspil, G. 2005. Adipocytokines and insulin resistance. 
Alimentary Pharmacology and Therapeutics; 22 (Suppl 2): 3- 10 .

75. Wang, J. Obici S, Morgan K, Barzilai N, Feng Z, Rossetti L. 2001. Overfeeding rapidly induces leptin and insulin resistance. Diabetes; 50: 2786-2791.

76. Weisberg, S.P., McCann, D., Desai, M., Rosenbaum, M., Leibel, R.L. and Ferrante, A.W. Jr. 2003. Obesity is associated with macrophage accumulation in adipose tissue. Journal of Clinical Investigation; 112: 17961808.

77. Weyer, C., Yudkin, J.S., Stenhouwer, C.D.A., Schalkwijk, C.G., Pratley, R.E. and Tataranni, P.A. 2002. Hormonal markers of inflammation and endothelial dysfunction in relation to adiposity and in vivo insulin action in Pima Indians. Atherosclerosis; 161: 233-42.

78. Wisse, B.E. 2004. The Inflammatory Syndrome: The role of adipose tissue cytokines in metabolic disorders linked to obesity. Journal of the American Society of Nephrology; 15: 2792- 2800.

79. Woronicz, J.D., Gao, X., Cao, Z., Rothe, M. and Goeddel, D.V. 1997. IkappaB kinase-beta: NF-kappaB activation and complex formation with IkappaB kinasealpha and NIK. Science; 278: 866-869.

80. Wu, X., Motoshima, H., Mahadev, K., Stalker, T.J., Scalia, R. and Goldstein, B.J. 2003. Involvement of AMP-activated protein kinase in glucose uptake stimulated by the globular domain of adiponectin in primary rat adipocytes. Diabetes; 52: 1355- 63.

81. Yamauchi, T., Kamon, J., Ito, Y., et al. 2003. Cloning of adiponectin receptors that mediate antidiabetic metabolic effects. Nature; 423: 762-9.

82. Yamauchi, T., Kamon, J., Minokoshi, Y., et al. 2002. Adiponectin stimulates glucose utilization and fatty-acid oxidation by activating AMP-activated protein kinase. Nature Medicine; 8:1288-95.

83. Zambon, A., Pauletto, P. and Crepaldi, G. 2005. The metabolic syndrome- a chronic cardiovascular inflammatory condition. Ailmentary Pharmacology \& Therapeutics; 22 (Suppl 2): 20 -23.

84. Zeng, M. Zhang H, Lowell C, He P. 2002. Tumor necrosis factor-alpha-induced leukocyte adhesion and microvessel permeability. American Journal of physiology. Heart and circulatory physiology 283: H2420- H2430.

85. Zoppini, G., Targher, G., Zamboni, C., et al. 2006. Effects of moderate-intensity exercise training on plasma biomarkers of inflammation and endothelial dysfunction in older patients with type 2 diabetes. Nutrition, Metabolisms and Cardiovascular Diseases; 16: 543-9.

86. Zwaka, T.P., Hombach, V. and Torzewski, J. 2001. Creactive protein- mediated low density lipoprotein uptake by macrophages: implications for atherosclerosis. Circulation; 103: 1194- 7. 